\title{
Squalene and cholesterol in dust from Danish homes and daycare centers
}

\author{
Weschler, Charles J.; Langer, Sarka; Fischer, Andreas; Bekö, Gabriel; Toftum, Jørn; Clausen, Geo
}

Published in:

Environmental Science \& Technology (Washington)

Link to article, DOI:

$10.1021 /$ es $103894 r$

Publication date:

2011

Document Version

Publisher's PDF, also known as Version of record

Link back to DTU Orbit

Citation (APA):

Weschler, C. J., Langer, S., Fischer, A., Bekö, G., Toftum, J., \& Clausen, G. (2011). Squalene and cholesterol in dust from Danish homes and daycare centers. Environmental Science \& Technology (Washington), 45(9), 38723879. https://doi.org/10.1021/es103894r

\section{General rights}

Copyright and moral rights for the publications made accessible in the public portal are retained by the authors and/or other copyright owners and it is a condition of accessing publications that users recognise and abide by the legal requirements associated with these rights.

- Users may download and print one copy of any publication from the public portal for the purpose of private study or research.

- You may not further distribute the material or use it for any profit-making activity or commercial gain

- You may freely distribute the URL identifying the publication in the public portal 


\title{
Squalene and Cholesterol in Dust from Danish Homes and Daycare Centers
}

\author{
Charles J. Weschler, ${ }^{+, \neq, *}$ Sarka Langer, ${ }^{\Perp, \S}$ Andreas Fischer, ${ }^{\S, \perp}$ Gabriel Bekö, ${ }^{\ddagger}$ Jørn Toftum, ${ }^{\ddagger}$ and Geo Clausen ${ }^{\ddagger}$ \\ ${ }^{\dagger}$ Environmental and Occupational Health Sciences Institute, University of Medicine and Dentistry of New Jersey and Rutgers University, \\ 170 Frelinghuysen Road, Piscataway, New Jersey 08854, United States \\ ${ }^{\ddagger}$ International Centre for Indoor Environment and Energy, Department of Civil Engineering, Technical University of Denmark, \\ DK-2800 Lyngby, Denmark \\ ${ }^{\S}$ Department of Chemistry and Materials Technology, SP Technical Research Institute of Sweden, Box 857, SE-501 15 Borås, Sweden \\ ${ }^{\perp}$ Department of Chemistry, Atmospheric Science, University of Gothenburg, SE-412 96 Göteborg, Sweden \\ S Supporting Information
}

ABSTRACT: Given the rate at which humans shed their skin (desquamation), skin flakes that contain squalene and cholesterol are anticipated to be major constituents of indoor dust. These compounds have been detected in more than $97 \%$ of the dust samples collected from 500 bedrooms and 151 daycare centers of young children living in Odense, Denmark. The mass fractions of squalene in dust were approximately log-normally distributed (homes: $\mathrm{GM}=32 \mu \mathrm{g} / \mathrm{g}$, GSD $=4.3$; daycare centers: $\mathrm{GM}=11.5 \mu \mathrm{g} / \mathrm{g}, \mathrm{GSD}=4.3)$; those of cholesterol displayed a

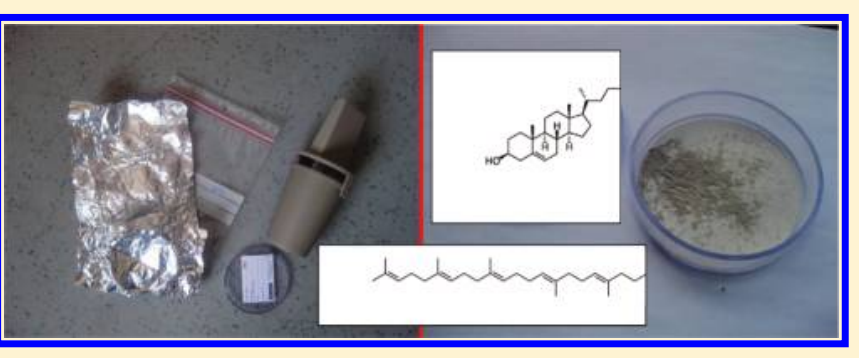
poorer fit to such a distribution (homes: $\mathrm{GM}=625 \mu \mathrm{g} / \mathrm{g}$, GSD $=3.4$; daycare centers: $\mathrm{GM}=220 \mu \mathrm{g} / \mathrm{g}, \mathrm{GSD}=4.0$ ). Correlations between squalene and cholesterol were weak $(r=0.22)$. Furthermore, the median squalene-to-cholesterol ratio in dust $(\sim 0.05)$ was more than an order of magnitude smaller than that in skin oil. This implies sources in addition to desquamation (e.g., cholesterol from cooking) coupled, perhaps, with a shorter indoor lifetime for squalene. Estimated values of squalene's vapor pressure, while uncertain, suggest meaningful redistribution from dust to other indoor compartments. We estimate that dust containing squalene at $60 \mu \mathrm{g} / \mathrm{g}$ would contribute about $4 \%$ to overall ozone removal by indoor surfaces. This is roughly comparable to the fraction of ozone removal that can be ascribed to reactions with indoor terpenes. Squalene containing dust is anticipated to contribute to the scavenging of ozone in all settings occupied by humans.

\section{INTRODUCTION}

The stratum corneum is the outermost layer of our skin. It consists chiefly of corneocytes surrounded by intercellular lamellar lipid membranes and, depending on the region of the body, is approximately 15 to 25 cell layers thick. ${ }^{1-3}$ Cholesterol is a major constituent of the intercellular lipids. ${ }^{4}$ The surface of the stratum corneum is covered by skin surface lipids. Both squalene and cholesterol are major constituents of skin surface lipids. ${ }^{5-8}$ The chemical structures of these compounds are displayed in Figure 1.

In a process referred to as desquamation, humans shed their entire outer layer of skin every 2 to 4 weeks. Humans shed about a thousand cells $/ \mathrm{cm}^{2} / \mathrm{h}$ or roughly $5 \times 10^{8}$ cells/day. ${ }^{1}$ A typical desquamated skin particle, referred to as a "squame", is roughly $40 \times 30 \times 2 \mu \mathrm{m}$, with a mass of $\sim 2.5 \mathrm{ng}$. ${ }^{9,10}$ This translates to a shedding rate per human of 30 to $90 \mathrm{mg}$ skin flakes/h. ${ }^{1,11,12}$ Given the rate at which humans shed their skin and the skin oils associated with these skin flakes, we anticipate that squalene and cholesterol should be major constituents of settled dust in any indoor environment that is occupied by humans. In 1973, Clark and Shirley ${ }^{13}$ reported the percentage of skin, by weight, present in size-fractionated airborne particles collected from various indoor locations. They based their assessment on the squalene content of airborne particles coupled with their measurement of the squalene present in typical skin flakes ( $\sim 1 \%$ by weight). A chromatogram in their article (Figure 2 in ref 13) also shows a peak for cholesterol, but its mass-fraction was not reported. Although cholesterol has subsequently been measured in outdoor airborne particles, ${ }^{14-20}$ we have been unable to find detailed measurements of squalene or cholesterol in indoor airborne particles. Additionally, we have found only two reports of these compounds in indoor settled dust. ${ }^{21,22}$ Schlitt et al. ${ }^{21}$ presented chromatograms of five house dust extracts, which display peaks for squalene and cholesterol. In each case, the peak of the latter was larger than that of the former, but neither compound was quantified. Øie et al. ${ }^{22}$ measured organic species in 38 house dust samples. They report squalene as one of the

Received: August 10, 2010

Accepted: March 27, 2011

Revised: February 26, 2011 


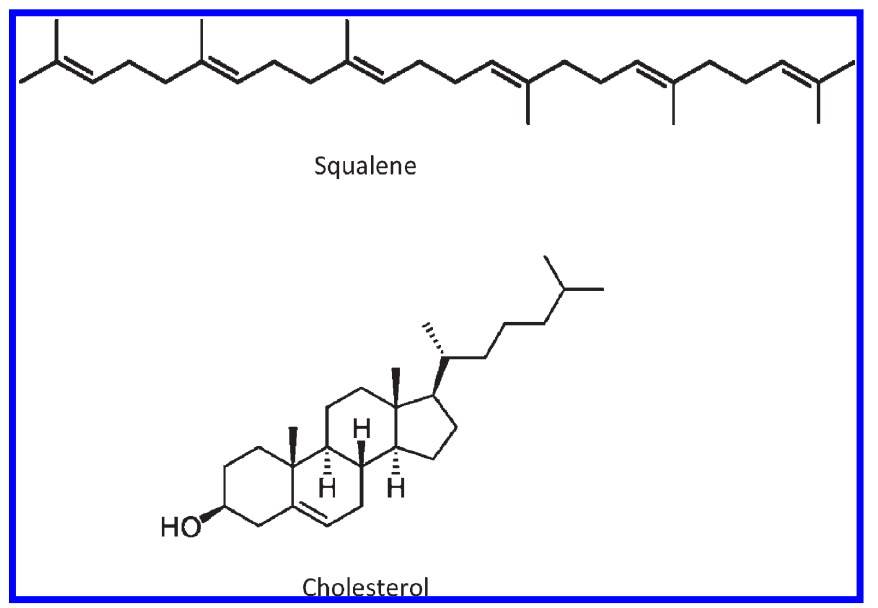

Figure 1. Chemical structures of squalene and cholesterol are displayed; note the six double bonds in squalene and the single double bond in cholesterol.

more prominent constituents, but do not report mass-fractions for this compound.

To examine this issue in greater detail, we have measured squalene and cholesterol mass fractions in dust samples collected as part of the ongoing Danish Indoor Environment and Children's Health (IECH) study. ${ }^{23}$ This is a multiyear, case-base investigation of potential associations between different indoor environmental factors and children's health, especially allergies and asthma. The study included the collection of dust samples from 500 bedrooms of children (ages 3 to 5) living in the city of Odense, Denmark, and its surroundings; dust was also collected from the 151 daycare centers that the children attended.

The aim of the present article is to report the mass-fraction of squalene and cholesterol in these dust samples; to examine potential sources for these two species in children's bedrooms and daycare facilities; and to discuss the implications of these findings with respect to indoor oxidation chemistry. Additionally, the mass-fractions of squalene and cholesterol in settled dust may provide information on their concentration in other indoor compartments, including air, airborne particles, and the organic matter on exposed indoor surfaces. ${ }^{24,25}$

\section{METHODS}

The dust collection procedures and chemical analysis have been previously described. ${ }^{26}$ In the following paragraphs we summarize these procedures; the Supporting Information contains further details.

Dust Collection. Dust was vacuumed from nonfloor surfaces in the children's bedrooms or daycare centers onto a cellulose-filter (ALK-Abelló A/S, Hørsholm, Denmark) mounted in a holder connected to a vacuum cleaner. In $2 \%$ of homes a second dust sample (duplicate) was collected. In 5\% of the homes (randomly chosen) a field blank was collected. Of the total filters that were analyzed, 33 were field blanks, 12 were duplicates, and 42 were laboratory blanks.

Prior to sampling, virgin filters were preconditioned at 50\% $\mathrm{RH}$ for at least $72 \mathrm{~h}$ before being weighed and labeled. After sampling, the loaded filters or blanks were wrapped in aluminum foil, placed in polyethylene bags and frozen until they were returned to the laboratory where they were conditioned at $50 \%$

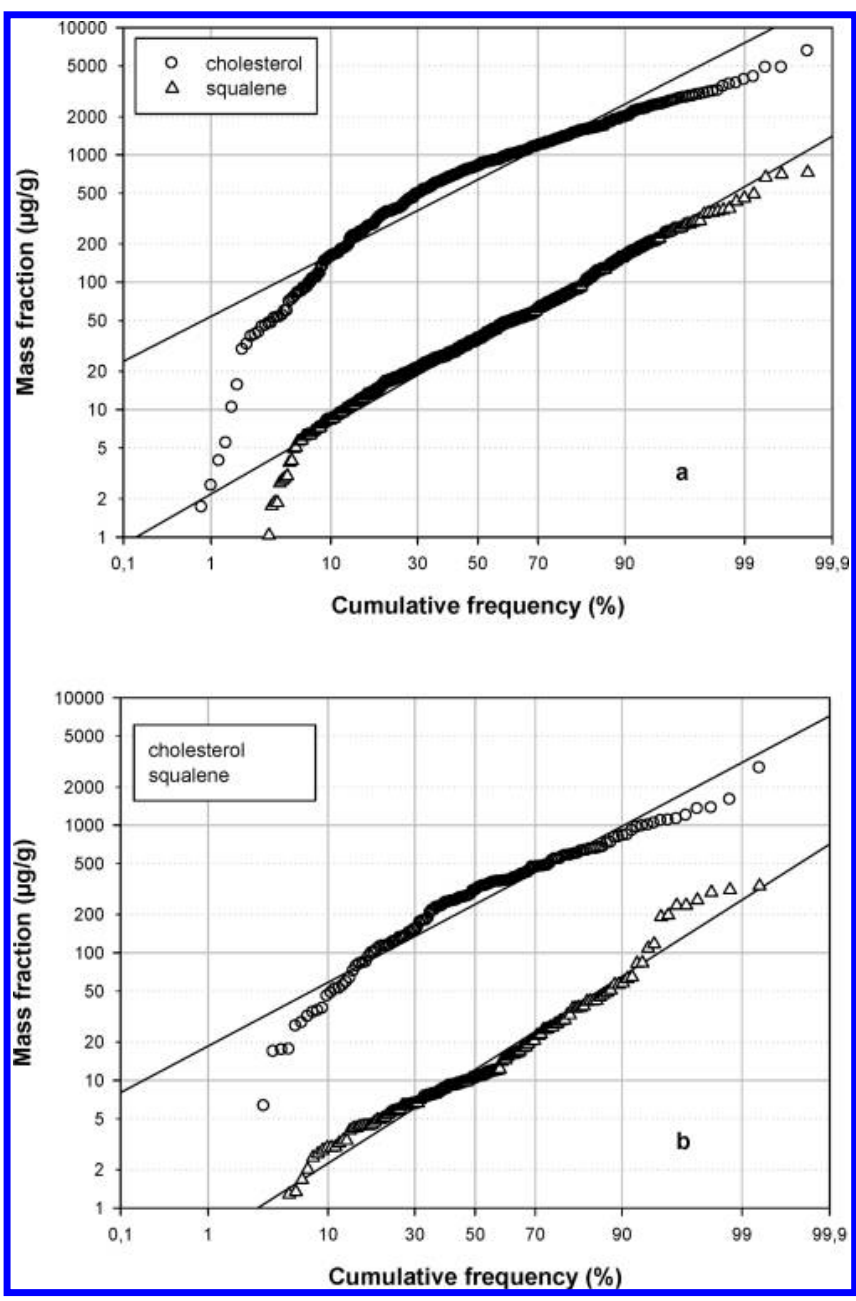

Figure 2. Cholesterol and squalene mass-fractions in dust from (a) children's bedrooms and (b) daycare centers are plotted against their cumulative frequency (\%). The $y$ axis is scaled logarithmically, whereas the $x$ axis is scaled for a normal distribution; hence, linearity is indicative of a log-normal distribution.

$\mathrm{RH}$ for at least $72 \mathrm{~h}$, weighed, repackaged, and refrozen. The net mass of dust on the loaded filters ranged from 40 to $1400 \mathrm{mg}$.

Chemical Analysis. The dust samples were extracted (without sieving) and analyzed following procedures similar to those described by Rudel et al. ${ }^{27}$ The samples were spiked with isotopically labeled internal standards (diethyl phthalate- $\mathrm{d}_{4}$, di- $n$ octyl phthalate- $\mathrm{d}_{4}$, chrysene- $\mathrm{d}_{12}$, and benzo[a]pyrene- $\mathrm{d}_{12}$ ) prior to extraction and analysis. The recoveries of these deuterated internal standards/recovery surrogates were $90 \%$ or larger in all samples and blanks. The spiked dust samples were ultrasonically extracted for $30 \mathrm{~min}$ using $15 \mathrm{~mL}$ of $n$-hexane with $6 \%$ diethyl ether; this procedure was then repeated. The two extracts were combined and concentrated to approximately $5 \mathrm{~mL}$. A $250 \mu \mathrm{L}$ aliquot was analyzed after adding 1,2,3,4-tetrachloronaphthalene as an injection standard. Analyses were performed on an Agilent Technologies $6890 \mathrm{~N}$ Gas Chromatograph equipped with a 5975 XL Mass Selective Detector (GC-MS) and a 7683 Series Autoinjector in a full scan acquisition mode $(29-650 \mathrm{amu})$. The analytical capillary column was BPX -5 ( $5 \%$ phenyl polysilphenylene siloxane), $25 \mathrm{~m}, 0.22 \mathrm{~mm}$ i.d., $0.25 \mu \mathrm{m}$ film thickness; ultrahigh purity helium was used as the carrier gas. 
Squalene and cholesterol were first identified in the dust extracts by matching their mass spectra in the total ion chromatogram (TIC) against mass spectra in the NIST Mass Spectral Library. Their identities were subsequently confirmed by matching their spectra and retention times against those of authentic samples of squalene (CAS 7683-64-9) and cholesterol (CAS 57-88-5). In the TIC of a typical dust sample, the mass spectra obtained at the retention times of squalene and cholesterol matched those of pure squalene and cholesterol, indicating the absence of significant spectral interference in either case. The target compounds were quantified using $m / z=69$ for squalene and $m / z=386$ for cholesterol, while using $m / z=266$ for tetrachloronaphthalene with the "Extraction Ion" procedure from the full scan chromatographs $(m / z=29-650)$. Calibration was performed using authentic squalene and cholesterol samples run in the same manner as the dust extracts.

The amounts of squalene found in the laboratory and field blanks were $0.7 \pm 0.9 \mu \mathrm{g} /$ filter and $2.1 \pm 2.5 \mu \mathrm{g} /$ filter, respectively; the amount of cholesterol in both laboratory and field blanks was below the limit of detection (Table S1 of the Supporting Information). The higher level of squalene in the field blanks compared to the lab blanks likely reflects a small amount of contamination from human skin oil. The estimated detection limits (from external calibration) were $0.4 \mu \mathrm{g}$ squalene/filter and $7 \mu \mathrm{g}$ cholesterol/filter.

The original target analytes in these dust samples were phthalate esters and PAHs. ${ }^{26}$ It was only after the samples had been extracted and the analysis had been performed that we recognized peaks in the TIC that corresponded to squalene and cholesterol. However, at this point all of the dust samples from the children's bedrooms and daycare centers had been extracted. Therefore, to determine the extraction efficiencies for squalene and cholesterol we used portions of indoor dust from a large sample similar to those collected in Odense. This same dust had been used to evaluate the effect of sample size on the phthalate and PAH results. ${ }^{26}$ Three separate portions of this substitute dust were spiked with squalane- $\mathrm{d}_{62}$ and cholesterol- $\mathrm{d}_{1}$. The samples were then extracted using the methods described above. The squalene recovery was $0.84 \pm 0.03$; the cholesterol recovery was $0.44 \pm 0.06$. The mass fractions reported in the present study have been adjusted based on these recoveries.

We acknowledge that the analytical procedures that we used for squalene and cholesterol were not optimal. If these compounds had been targeted from the beginning, we would have spiked all of the samples with isotopically labeled squalene and cholesterol prior to analysis. The recoveries of labeled cholesterol from the portions of substitute indoor dust are indicative of suboptimal extraction using the solvent mixture and sonication procedure that was employed. In hindsight, the cholesterol measurements would have been more accurate if we had derivatized a portion of the extract with bis-(trimethylsilyl) trifluoroacetamide (BSTFA) to convert cholesterol to its trimethylsilyl derivative. ${ }^{19}$ Although the cholesterol values are less than perfect, we judge that they are accurate enough (better than a factor of 2) to support the major findings of this article. The recoveries of labeled squalene from the portions of substitute indoor dust are acceptable and consistent with the fact that squalene was readily extracted from the dust using the solvent mixture and procedures that we employed. Squalene chromatographed well, resulting in peaks that were easily integrated. We judge that the squalene measurements have an overall accuracy of $25 \%$.
Table 1. Geometric Mean (Geometric Standard Deviation) and 5th, 25th, 50th, 75th, and 95th Percentiles for MassFractions $(\mu \mathrm{g} / \mathrm{g})$ of Squalene and Cholesterol in Dust Samples Collected from Children's Bedrooms and Daycare Centers

\begin{tabular}{lrrrrrr} 
compound & GM (GSD) & 5th \% & 25th \% & 50th \% & 75th \% & 95 th \% \\
squalene & $32.4(4.3)$ & 3.9 & 18.5 & 36.0 & 72.9 & 243 \\
cholesterol & $625(3.4)$ & 73 & 386 & 809 & 1300 & 2545 \\
& \multicolumn{7}{c}{ Bedrooms } \\
squalene & $11.5(4.3)$ & 1.3 & 5.9 & 10.6 & 26.2 & 155 \\
cholesterol & $220(4.0)$ & 22 & 128 & 307 & 514 & 1059 \\
\hline
\end{tabular}

\section{RESULTS AND DISCUSSION}

Mass Fractions in Dust. Reliable measurements of squalene and cholesterol were obtained for dust samples from 495 homes (1 sample lost, 4 with analytical issues) and from all 151 daycare centers (Table S2 of the Supporting Information contains information on nondetects). Figure 2a presents log-probability plots for squalene and cholesterol mass fractions in homes. The $y$ axis is scaled logarithmically, whereas the $x$ access displays the cumulative frequency, in percent, scaled for a normal distribution. Part b of Figure 2 is an analogous plot for daycare centers. For squalene, in both homes and daycare centers, the plots are linear between the 10th and 90th percentiles, indicating that the distribution of the mass-fractions is reasonably approximated as log-normal. Close to log-normal distributions have also been observed for phthalate ester and $\mathrm{PAH}$ mass fractions measured in these same dust samples, ${ }^{26}$ for indoor volatile organic compounds, ${ }^{28,29}$ and are anticipated for environmental pollutants in general. ${ }^{30}$ In contrast the plots for cholesterol display curvature and may reflect two or more different and substantial sources, each with its own inherent distribution.

A total of 16 semivolatile organic compounds (SVOCs) were quantified in the dust samples (squalene, cholesterol, five phthalate esters, three PAHs, and six other species). Among these 16 SVOCs, cholesterol was the most abundant and squalene was the third most abundant in the bedroom dust samples, whereas cholesterol was the second most abundant and squalene was the sixth most abundant in daycare centers.

Table 1 lists geometric means and geometric standard deviations, as well as 5th, 25th, 50th, 75th, and 95th percentiles for squalene and cholesterol in dust samples collected from the children's bedrooms and daycare centers. The median levels of cholesterol are roughly 20 times larger than those of squalene in both the children's bedrooms ( $625 \mathrm{vs} 32 \mu \mathrm{g} / \mathrm{g}$ ) and the daycare centers $(220$ vs $12 \mu \mathrm{g} / \mathrm{g})$. The levels of these compounds are roughly three times larger in the bedrooms than in the daycare centers. This stands in contrast with $\operatorname{di}(n$-butyl) phthalate (DnBP), butylbenzyl phthalate (BBzP), and di(2-ethylhexyl) phthalate (DEHP), each common plasticizers, whose levels are larger in the daycare centers. ${ }^{26}$ In part, this may reflect the facts that bedrooms are occupied for a larger percentage of the day, clothes are changed more commonly in the bedroom, and bedrooms tend to be cleaned less frequently, whereas daycare centers tend to have more vinyl toys and vinyl containing products. Cooking (primarily electric ovens and ranges) occurs at both locations; little indoor smoking occurs at either setting. 
Table 2. Mass Fraction $(\mu \mathrm{g} / \mathrm{g})$ of Squalene in Size-Fractioned Airborne Particles Sampled by Clark and Shirley ${ }^{13}$ in Various Indoor Environments

\begin{tabular}{llll} 
& \multicolumn{3}{c}{ Particle size range } \\
& $\mathbf{0 . 4 - 0 . 7} \boldsymbol{\mu m}$ & $\mathbf{0 . 7}-\mathbf{2 . 0} \boldsymbol{\mu m}$ & $\mathbf{2 . 0}-\mathbf{6 . 0} \boldsymbol{\mu m}$ \\
house & $80 \mu \mathrm{g} / \mathrm{g}$ & $70 \mu \mathrm{g} / \mathrm{g}$ & $40 \mu \mathrm{g} / \mathrm{g}$ \\
lab corridor & $50 \mu \mathrm{g} / \mathrm{g}$ & $50 \mu \mathrm{g} / \mathrm{g}$ & $100 \mu \mathrm{g} / \mathrm{g}$ \\
& $\mathbf{0 . 3}-\mathbf{2 . 0} \boldsymbol{\mu \mathrm { m }}$ & $\mathbf{2 . 0}-\mathbf{3 . 5} \boldsymbol{\mu \mathrm { m }}$ & $\mathbf{3 . 5}-\mathbf{5 . 5} \boldsymbol{\mu m}$ \\
London underground & $1000 \mu \mathrm{g} / \mathrm{g}$ & $1000 \mu \mathrm{g} / \mathrm{g}$ & $1000 \mu \mathrm{g} / \mathrm{g}$ \\
\hline
\end{tabular}

As noted in the Introduction, Clark and Shirley ${ }^{13}$ measured the percentage of skin (by weight) in airborne particles collected from various indoor locations. From their reported data, it is straightforward to calculate the mass fraction of squalene in the various size-fractions of airborne particles that they collected. Depending on the sampling location and size range, the measured mass fraction of squalene in airborne particles ranged from 40 to $1000 \mu \mathrm{g} / \mathrm{g}$ (Table 2). For airborne particles in the $2-6 \mu \mathrm{m}$ size range collected in either a house or laboratory corridor, the reported values were 40 and $100 \mu \mathrm{g} / \mathrm{g}$, respectively; such values are consistent with the geometric mean of $32 \mu \mathrm{g} / \mathrm{g}$ measured in the present study. Although squalene and cholesterol have been previously identified in indoor settled dust, we could find no prior quantitative analysis of either compound in such samples.

Table 3 shows interspecies correlations for squalene and cholesterol, as well as for the three PAHs, five phthalate esters and nicotine, measured in the dust samples from homes (bottom) and daycare centers (top). Also included is average $\mathrm{CO}_{2}$ measured over two or more days in the children's bedrooms and during time periods when the daycare centers were open. As previously noted, ${ }^{26}$ the correlations among the three PAH are strong, especially at the home locations. None of the other correlations approach this level. Squalene is weakly correlated with cholesterol at both locations $(r=0.22$ for each $)$ and $\mathrm{CO}_{2}$ at daycare centers $(r=0.22)$. Cholesterol is weakly correlated with diethyl phthalate (DEP, $r=0.24$ ) in daycare centers but not homes, which may reflect co-occurrence in certain consumer products. It is also correlated with $\mathrm{CO}_{2}$ in homes $(r=0.20)$ and daycare centers $(r=0.54)$, which may be due to coemission during cooking. However, these $r$ values are low and such assignments are highly speculative. Although cholesterol and the sum of PAH were correlated in outdoor PM2.5 samples collected at urban $(r=0.85)$ and rural $(r=0.76)$ sites in England, ${ }^{20}$ no such correlation was observed in these samples of indoor settled dust.

Sources and Sinks for Squalene and Cholesterol. As noted above, squalene and cholesterol are weakly correlated in dust samples from both the bedrooms and daycare centers. Further information on the relationship between squalene and cholester$\mathrm{ol}$ is provided by the ratios of their mass fractions in dust. The median for the ratio of squalene to cholesterol is 0.053 for the bedroom dust samples and 0.049 for the daycare dust samples. It is instructive to compare these ratios with those anticipated if humans were the only source of these compounds.

At the surface of human skin, lipids from the sebaceous gland mix with intercellular lipids from the stratum corneum to generate skin surface lipids. ${ }^{5}$ The lipids from the sebaceous gland are rich in squalene and poor in cholesterol; the reverse is true for intercellular lipids from the stratum corneum. The skin surface lipids of children between 1 month and 8 years of age are typically
6 to $9 \%$ squalene, 4 to $7 \%$ cholesterol, with a squalene to cholesterol ratio in the range of 1.1 to $2.5 .^{7,8,31}$ The skin surface lipids of adults, who have greater sebaceous gland activity, are typically $10 \%$ squalene, 2 to $3 \%$ cholesterol, with a squalene to cholesterol ratio in the range of 3 to 9., ${ }^{5,6}$ The ratio of squalene-tocholesterol in the stratum corneum is much lower than in skin oil - typically 0.2 to $0.5 .^{4}$ For both skin surface lipids and intercellular lipids of the stratum corneum, the ratio of squalene to cholesterol varies with the location on the body from which the sample is taken. ${ }^{4,6}$

It is anticipated that desquamated skin cells leave the body coated with skin oil. However, we have not found any reports in the literature on the ratio of squalene-to-cholesterol in squames (desquamated cells). There are studies that report the massfractions of either squalene or cholesterol in skin scraped from humans, but not studies which reported results for both compounds at the same time. Clark and Shirley ${ }^{13}$ used a scalpel to dislodge skin scales from a human (they do not indicate where on the body) and report that these skin scales have a squalene content of $1 \%$ or $10000 \mu \mathrm{g} / \mathrm{g}$. Figure 2 of this same article presents a "chromatogram of the fats on skin scale scraped from the body surface" that includes peaks identified as cholesterol and squalene. Visually, the squalene peak appears to be about 5 times larger than the cholesterol peak, but the cholesterol mass-fraction is not reported and the response of the instrument to these two compounds may have differed. Schmidt et al. ${ }^{32}$ measured cholesterol in skin scales scraped from the sole of the foot and from the leg and back (combined) of a number of human volunteers. They report a median mass-fraction of $1700 \mu \mathrm{g} / \mathrm{g}$ from the sole and $1600 \mu \mathrm{g} / \mathrm{g}$ from the leg/back. Taken together, these two studies suggest that mass-fraction of squalene on squames is larger than that of cholesterol.

The ratios of squalene to cholesterol measured in children's and adults' skin oil and inferred in desquamated cells $(\sim 1$ to 9$)$ stand in contrast to those measured in settled dust from the bedrooms and daycare centers $(\sim 0.05)$. The observed differences between these ratios suggest other indoor sources for cholesterol besides human skin flakes and/or a significantly shorter lifetime for squalene compared with cholesterol once these compounds enter an indoor environment.

Other likely indoor sources of cholesterol include cooking, skin care products and outdoor-to-indoor transport of cholesterol-containing particles. Other potential indoor sources of squalene include shark liver oil, olive oil $(<1 \%$ by weight $)$ and certain personal care products. It is known that cholesterol is a meaningful constituent of organic aerosols generated by meat charbroiling and cooking. ${ }^{14,16}$ Other foods and cooking fats also contain cholesterol. Hence, cooking in both homes and daycare centers is expected to be a meaningful source of cholesterol, but a less important source of squalene. Interestingly, the skin oils of most other mammals, including dogs and cats, do not contain large concentrations of squalene but do contain substantial levels of cholesterol. $^{5,33-35}$

Cholesterol has been measured in outdoor airborne particles of various sizes collected in southern California, Pittsburgh, PA, Beijing, and both urban and background sites in the UK; ${ }^{14-20}$ reported levels ranged from beneath detection limits to $3.3 \mathrm{ng}$ cholesterol $/ \mathrm{m}^{3}$ air. The investigators have suggested that the cholesterol in these outdoor particles came from meat cooking and, perhaps, aerosols generated by sea spray for locations close to the ocean. Only Harrison and Yin $^{20}$ provide sufficient information to calculate the mass fraction of cholesterol in 
Table 3. Correlations among Various SVOCs in the Settled Dust, as well as Gas Phase $\mathrm{CO}_{2}$, for Samples from the Children's Bedrooms (Bottom) and from Their Daycare Centers (Top)

\begin{tabular}{|c|c|c|c|c|c|c|c|c|c|c|c|c|c|c|}
\hline & & \multicolumn{13}{|c|}{ Day Care Centers } \\
\hline & & Pyrene & $\mathrm{BaA}$ & BaP & SumPAH & DEP & DnBP & DiBP & BBzP & DEHP & Nicotine & Squalene & Cholesterol & $\mathrm{CO}_{2}{ }^{\mathrm{b}}$ \\
\hline \multirow{13}{*}{$\begin{array}{l}\text { y } \\
\text { 동 } \\
\text { 오 }\end{array}$} & Pyrene & - & 0.66 & 0.53 & 0.97 & 0.08 & 0.05 & 0.08 & -0.08 & -0.01 & 0.21 & -0.03 & 0.06 & 0.10 \\
\hline & $\mathrm{BaA}$ & 0.90 & - & 0.67 & 0.80 & -0.01 & 0.04 & 0.06 & -0.08 & -0.05 & 0.08 & -0.01 & 0.02 & 0.05 \\
\hline & BaP & 0.90 & 0.95 & - & 0.70 & 0.09 & 0.16 & 0.12 & -0.11 & \begin{tabular}{|l|}
-0.02 \\
\end{tabular} & 0.11 & -0.06 & 0.02 & 0.11 \\
\hline & SumPAH & 0.98 & 0.96 & 0.96 & - & 0.07 & 0.08 & 0.09 & -0.09 & \begin{tabular}{|l|}
-0.02 \\
\end{tabular} & 0.20 & -0.03 & 0.05 & 0.10 \\
\hline & DEP & -0.01 & -0.03 & -0.03 & -0.02 & - & 0.13 & 0.09 & 0.00 & -0.01 & 0.15 & -0.04 & 0.24 & 0.09 \\
\hline & DnBP & 0.05 & 0.02 & 0.03 & 0.04 & 0.12 & - & 0.23 & 0.08 & 0.21 & -0.04 & 0.04 & 0.10 & 0.18 \\
\hline & DiBP & 0.01 & 0.00 & -0.01 & 0.00 & 0.00 & 0.02 & - & -0.06 & -0.09 & 0.03 & 0.04 & 0.11 & 0.07 \\
\hline & BBzP & 0.03 & 0.01 & -0.01 & 0.02 & 0.02 & 0.04 & -0.02 & - & 0.27 & -0.07 & -0.04 & 0.12 & 0.00 \\
\hline & DEHP & -0.02 & -0.05 & -0.04 & -0.03 & 0.00 & 0.15 & -0.03 & 0.03 & - & -0.05 & -0.08 & -0.13 & -0.06 \\
\hline & Nicotine & 0.02 & 0.00 & -0.01 & 0.01 & 0.02 & 0.11 & 0.02 & -0.02 & 0.12 & - & 0.05 & 0.11 & 0.01 \\
\hline & Squalene & 0.04 & 0.01 & 0.00 & 0.03 & -0.03 & 0.07 & 0.06 & -0.03 & 0.00 & -0.04 & - & 0.22 & 0.22 \\
\hline & Cholesterol & -0.04 & -0.07 & -0.08 & -0.06 & 0.04 & 0.10 & 0.04 & -0.02 & -0.08 & 0.01 & 0.22 & - & 0.54 \\
\hline & $\mathrm{CO}_{2}{ }^{\mathrm{a}}$ & 0.01 & -0.04 & -0.01 & -0.01 & 0.00 & -0.01 & 0.13 & -0.02 & 0.13 & 0.08 & 0.02 & 0.20 & - \\
\hline
\end{tabular}

airborne particles. Based on median concentrations of cholester$\mathrm{ol}$ and PM2.5 measured at the sites, the mass fraction of cholesterol in urban and rural background PM2.5 was 11 and $13 \mu \mathrm{g} / \mathrm{g}$, respectively. It is likely that a small fraction of the cholesterol measured in settled dust samples from Odense came from outdoor particles transported into the children's homes or daycare centers. However, the extent of such a contribution is difficult to estimate.

Ozone reacts with squalene faster than with oleic acid, ${ }^{36}$ but it reacts with cholesterol slower than with oleic acid. ${ }^{37-39}$ The measured reaction probability for ozone with squalene ${ }^{36}$ is approximately 2 orders of magnitude larger than that with cholesterol $^{38}\left(3 \times 10^{-4}\right.$ to $4.5 \times 10^{-4}$ vs $2.6 \times 10^{-6}$ to $2.9 \times$ $\left.10^{-6}\right)$. Hence, squalene is anticipated to have a much shorter indoor lifetime than cholesterol, given the rates at which they are oxidized. If we assume a second order, gas-phase rate coefficient of $6.4 \times 10^{-5} \mathrm{ppb}^{-1} \mathrm{~s}^{-1}$ for ozone with squalene $\mathrm{s}^{36}$ and $5 \times 10^{-7}$ $\mathrm{ppb}^{-1} \mathrm{~s}^{-1}$ for ozone with cholesterol, ${ }^{39}$ then at an average indoor ozone level of $5 \mathrm{ppb}$, the half-life of squalene is roughly half an hour while that of cholesterol is more than 3 days. We must be cautious regarding such an analysis. We know neither the mean age of settled dust nor how the mean age varies from bedroom to bedroom or daycare center to daycare center. Additionally, there are differences between ozone reacting with an isolated organic compound and reacting with that same compound present in a mixture. For example, a study by Weitkamp et al. ${ }^{39}$ of ozone reacting with cholesterol, oleic acid and palmitoleic acid within meat grease aerosols indicates that factors such as relative humidity and particle composition (which presumably extends to dust composition) can affect the oxidation of different unsaturated species in different ways.

In summary, the above analyses suggest that squalene in the dust samples is derived from desquamated human skin and, to a lesser extent, personal care products. Cholesterol is also derived from desquamated human skin, but this source appears to make a smaller contribution to its overall presence in dust than does cooking. Other potential sources include particles of outdoor origin that become part of the settled dust and perhaps skin flakes from pets. Additionally, the indoor lifetime of squalene with respect to ozone appears to be much shorter than that of cholesterol. The next section provides further information regarding possible sources and sinks for these two species.

Linear regression modeling. The IECH Study (Introduction) acquired information on a number of variables related to the children's homes. ${ }^{40}$ Multiple regression models were developed to test associations between these variables and the naturallogarithms of the mass fractions of squalene and cholesterol in the bedroom dust. The analyses were performed using STATA software, release 11.0 (StataCorp LP, College Station, Texas, USA). The final linear regression models retained variables with a significance level of $p<0.2$ in the stepwise selection procedure. The most successful squalene model regressed $\ln$ (squalene) on 12 variables, whereas the most successful cholesterol model regressed $\ln$ (cholesterol) on 10 variables. Tables S3 and S4 of the Supporting Information present coefficients, factor values, confidence intervals, and $p$-values in the squalene and cholesterol models, respectively. Variability in squalene can be modeled slightly better than variability in cholesterol $\left(R^{2}=0.12\right.$ compared to $R^{2}=0.08$, respectively), although neither model explains the majority of the measured variability. Variables included in both the squalene and cholesterol models were occupant density (number $/ \mathrm{m}^{3}$ sleeping in the child's bedroom), air change rate, number of people living in the home, use of an air freshener, family member with allergies, and presence of a gas stove. It is noteworthy that occupant density was a statistically more reliable variable for squalene than for cholesterol ( $p=0.00$ vs $p=0.20)$. Only 21 of the 490 homes with available data had gas stoves; higher levels of squalene and cholesterol in these homes may reflect lower ozone concentrations due to its titration by nitric oxide emitted during gas-cooking. Other significant variables in the squalene model were number of pets, outdoor temperature, mechanical ventilation, potted plants, condensation in winter on bedroom windows and fireplace use. Other significant variables for the cholesterol model included presence of mold, kitchen exhaust hood, smoking, and certain foods in the home (based on a questionnaire administered 1 to 3 months prior to dust 
collection). The fact that the sum of key foods (e.g., meats, fish, cooking oils) in a home is a significant variable for cholesterol but not for squalene is consistent with cooking as a source of the former. Variables related to the type, location and construction of the building, cleaning and ventilation habits, renovation of the home and other behavioral descriptors were tested in both models but lacked explanatory power.

Tables S5 and S6 of the Supporting Information present descriptive statistics for the variables, as well as squalene and cholesterol mass-fractions (median and geometric means) for different values of the variables. In Table S5 of the Supporting Information, it is noteworthy how the squalene mass-fractions in dust vary with the number of people living in a home and the occupant density in the bedroom. For example, for homes with 2 or 3 occupants $(n=90)$ the median squalene mass-fraction is $25 \mu \mathrm{g} / \mathrm{g}$ while for 6 or 7 occupants $(n=25)$, the median is $51 \mu \mathrm{g} / \mathrm{g}$. Similarly, for bedrooms with an occupant density between 0.015 and 0.045 occupants $/ \mathrm{m}^{3}(n=165)$, the median squalene value is $33 \mu \mathrm{g} / \mathrm{g}$, whereas for bedrooms with an occupant density larger than 0.067 occupants $/ \mathrm{m}^{3}(n=165)$, the median squalene value is $46 \mu \mathrm{g} / \mathrm{g}$. In Table S6 of the Supporting Information, we also see larger cholesterol mass-fractions in the dust when more people are living in the home or when the occupant density in the bedroom is larger. Additionally, smoking and the presence of certain key foods have an impact on the mass-fractions of cholesterol in the dust. In homes with no smokers $(n=368)$ the median value for cholesterol is $806 \mu \mathrm{g} / \mathrm{g}$, while in homes with indoor smokers $(n=26)$ the median value is $962 \mu \mathrm{g} / \mathrm{g}$. In homes with 0 to 4 key foods $(n=60)$, the median cholesterol massfraction is $605 \mu \mathrm{g} / \mathrm{g}$, whereas in homes with 6 or more key foods $(n=350)$ the median value is larger than $863 \mu \mathrm{g} / \mathrm{g}$. The Supporting Information contains further details on the variables included in the models as well as the quality of the models.

Potential Redistribution to Other Indoor Compartments. The potential for squalene or cholesterol to redistribute from settled dust to other indoor compartments (e.g., gas phase, airborne particles, indoor surfaces) depends on their respective vapor pressures and octanol/air partition coefficients. ${ }^{24}$ We have been unable to find measured vapor pressures $\left(P_{\mathrm{s}}\right)$ or octanol/air partition coefficients $\left(K_{\text {oa }}\right)$ for either of these compounds in the peer reviewed literature. We have estimated $P_{\mathrm{s}}$ and $K_{\mathrm{oa}}$ for these two species using three different packages for predicting chemical properties: SPARC Online Calculator, September 2009 release w4.5, ${ }^{41}$ http://ibmlc2.chem.uga.edu/sparc; U.S. EPA EPI Suite 4.0, http://www.epa.gov/oppt/exposure/pubs/episuite.htm; and ACD/Laboratories, http://www.chemspider.com. Table S7 of the Supporting Information summarizes the results. The estimated vapor pressures differ by more than 2 orders of magnitude for squalene and by more than 3 orders of magnitude for cholesterol. There is a similar lack of agreement for the octanol/ air partition coefficients. Results from both SPARC and ACD Laboratories indicate that squalene is much more volatile than cholesterol, while EPI Suite predicts similar volatility for these two compounds. In the case of squalene, even the most conservative estimate of $P_{\mathrm{S}}$ (SPARC) indicates that meaningful redistribution will occur over time - comparable to what is observed for di(2-ethylhexyl) phthalate. The larger estimates of $P_{\mathrm{s}}$ (EPI Suite and ACD Laboratories) translate to even greater redistribution within a given time interval. In the case of cholesterol, the estimates of an extremely low $P_{\mathrm{s}}$ (SPARC and ACD Laboratories) indicate that redistribution is negligible, whereas the EPI Suite estimate indicates meaningful redistribution. Given the ubiquity of these compounds in indoor environments and the important role of squalene in indoor oxidation chemistry (below), experimental determination of their $P_{\mathrm{s}}$ and $K_{\mathrm{oa}}$ values would be valuable, as would be measurements of their levels in other indoor compartments (e.g., airborne particles, window films, and surface wipes).

Implications for Indoor Ozone. It is only within the last five years that we've grown to appreciate the central role that squalene (from human skin oil) plays in oxidation chemistry within indoor environments. ${ }^{42-47}$ More than half of the ozone removal measured in a simulated aircraft cabin was found to be a consequence of ozone reacting with exposed skin, hair, and clothing of passengers. ${ }^{43}$ Of the five oxidation products produced in the largest yields, four were derived from skin oil and three of these were from squalene. ${ }^{44}$ In a simulated office setting, two occupants reduced the steady-state ozone level by roughly a factor of 2 , and, when the occupants were present, the major gas phase oxidation products were derived from squalene. ${ }^{47}$ Of the constituents of skin oil, squalene - with its 6 double bonds - is responsible for about $40 \%$ of the ozone removal on exposed skin and hair. ${ }^{46,47}$

In the absence of indoor sources, ozone's indoor concentration is a function of its outdoor concentration, its penetration efficiency, the outdoor-indoor air exchange rate and the rate at which it is consumed by gas-phase and surface processes. ${ }^{48} \mathrm{On}$ the basis of a number of studies, ozone's removal by indoor surfaces occurs with a rate constant typically in the range of 2.5 to $4 \mathrm{~h}^{-1} \cdot{ }^{48,49}$ To what extent might squalene, both in dust and perhaps also sorbed to indoor surfaces, contribute to the heterogeneous removal of indoor ozone? For commonly occurring indoor conditions, we estimate that settled dust containing squalene at $36 \mu \mathrm{g} / \mathrm{g}$ (median for bedroom dust) would remove ozone with a rate constant of $\sim 0.07 \mathrm{~h}^{-1}$. If the dust contained squalene at $243 \mu \mathrm{g} / \mathrm{g}$ (95th percentile value for bedroom dust), we estimate a contribution to ozone removal of $0.5 \mathrm{~h}^{-1}$. For comparison, we calculate that limonene at $5 \mathrm{ppb}$ together with $\alpha$-pinene, $\beta$-pinene, and $\Delta^{3}$-carene each at $2 \mathrm{ppb}$ (common indoor concentrations ${ }^{50}$ ) remove ozone with a rate constant of $0.12 \mathrm{~h}^{-1}$. Details regarding these calculations are presented in the Supporting Information.

Surface soiling by squalene is anticipated to introduce a commonality among all indoor environments that are occupied by humans. These calculations suggest that squalene in settled dust and sorbed to indoor surfaces contributes, in a small way, to the indoor removal of ozone - on a scale similar to ozone removal by terpenes.

\section{ASSOCIATED CONTENT}

S Supporting Information. Tables of further details on dust collection, chemical analysis, linear regression modeling, and the surface and gas phase kinetic calculations. This material is available free of charge via the Internet at http://pubs.acs.org.

\section{AUTHOR INFORMATION}

\section{Corresponding Author}

*E-mail: weschlch@umdnj.edu, phone: 732 235-4114, fax: 732 235-4569.

\section{Present Addresses}

"IVL Swedish Environmental Research Institute Ltd., P.O. Box 5302, SE-400 14 Gothenburg, Sweden 


\section{ACKNOWLEDGMENT}

The authors thank Glenn Morrison, William Nazaroff, and Armin Wisthaler for valuable discussions. We thank the families for their participation and the home inspectors who assisted with the collection of the dust samples. This study was generously supported by the Villum Foundation. The Swedish research council FORMAS is acknowledged for supporting Andreas Fischer through Ph.D. grant no. 2007-571, "Stealth compounds in indoor air".

\section{REFERENCES}

(1) Milstone, L. M. Epidermal desquamation. J. Derm. Sci. 2004, 36 (3), 131-140.

(2) Tobin, D. J. Biochemistry of human skin - our brain on the outside. Chem. Soc. Rev. 2006, 35 (1), 52-67.

(3) Elias, P. M. Epidermal lipids, barrier function, and desquamation. J. Invest. Dermatol. 1983, 80, S44-S49.

(4) Lampe, M. A.; Burlingame, A. L.; Whitney, J.; Williams, M. L.; Brown, B. E.; Roitman, E.; Elias, P. M. Human stratum-corneum lipids characterization and regional variations. J. Lipid Res. 1983, 24 (2), $120-130$.

(5) Nicolaides, N. Skin lipids: their biochemical uniqueness. Science 1974, 186 (4158), 19-26.

(6) Nikkari, T.; Schreibman, P. H.; Ahrens, E. H., Jr. In vivo studies of sterol and squalene secretion by human skin. J. Lipid Res. 1974, 15 (6), 563-73.

(7) Ramasastry, P.; Downing, D. T.; Pochi, P. E.; Strauss, J. S. Chemical composition of human skin surface lipids from birth to puberty. J. Invest. Dermatol. 1970, 54 (2), 139-44.

(8) Pochi, P. E.; Strauss, J. S.; Downing, D. T. Age-related changes in sebaceous gland activity. J. Invest. Dermatol. 1979, 73 (1), 108-11.

(9) McGinley, K. J.; Marples, R. R.; Plewig, G. A method for visualizing and quantitating the desquamating portion of the human stratum corneum. J. Invest. Dermatol. 1969, 53 (2), 107-11.

(10) Plewig, G. Regional differences of cell sizes in the human stratum corneum. II. Effects of sex and age. J. Invest. Dermatol. 1970, 54 (1), 19-23.

(11) Baker, H.; Kligman, A. M. Technique for estimating turnover time of human stratum corneum. Arch. Dermatol. 1967, 95 (4), 408-11.

(12) Egelrud, T. Desquamation in the stratum corneum. Acta Derm. Venereol. Suppl. (Stockh.) 2000, 208, 44-5.

(13) Clark, R. P.; Shirley, S. G. Identification of skin in airborne particulate matter. Nature 1973, 246 (5427), 39-40.

(14) Rogge, W. F.; Hildemann, L. M.; Mazurek, M. A.; Cass, G. R.; Simonelt, B. R.T. Sources of Fine Organic Aerosol 1. Charbroilers and Meat Cooking Operations. Environ. Sci. Technol. 1991, 25 (6), 11121125 .

(15) Rogge, W. F.; Mazurek, M. A.; Hildemann, L. M.; Cass, G. R.; Simoneit, B. R. T. Quantification of urban organic aerosols at a molecular-level -- identification, abundance and seasonal variation. Atmos. Environ. A 1993, 27 (8), 1309-1330.

(16) Schauer, J. J.; Kleeman, M. J.; Cass, G. R.; Simoneit, B. R. T. Measurement of emissions from air pollution sources. 1. C-1 through C-29 organic compounds from meat charbroiling. Environ. Sci. Technol. 1999, 33 (10), 1566-1577.

(17) Fine, P. M.; Chakrabarti, B.; Krudysz, M.; Schauer, J. J.; Sioutas, C. Diurnal variations of individual organic compound constituents of ultrafine and accumulation mode particulate matter in the Los Angeles basin. Environ. Sci. Technol. 2004, 38 (5), 1296-1304.

(18) Robinson, A. L.; Subramanian, R.; Donahue, N. M.; BernardoBricker, A.; Rogge, W. F. Source apportionment of molecular markers and organic aerosols 3. Food cooking emissions. Environ. Sci. Technol. 2006, 40 (24), 7820-7827.

(19) Jiang, Y. L.; Hou, X. M.; Zhuang, G. S.; Li, J.; Wang, Q. Z.; Zhang, R.; Lin, Y. F. The sources and seasonal variations of organic compounds in PM2.5 in Beijing and Shanghai. J. Atmos. Chem. 2009, 62 (3), 175-192.

(20) Harrison, R. M.; Yin, J. X. Chemical speciation of PM2.5 particles at urban background and rural sites in the UK atmosphere. J. Environ. Monit. 2010, 12 (7), 1404-1414.

(21) Schlitt, H.; Schauenburg, H.; Knoppel, H. Analysis of SVOC in house dust and indoor air: Adaptation and first application of an on-line SF-GC-MS combination; Jaakkola, J., Ilmarinen, R.; Seppanen, O., Eds.; Proceedings of Indoor Air '93, 1993, Vol. 2, 251-256.

(22) Øie, L.; Hersoug, L. G.; Madsen, J. O. Residential exposure to plasticizers and its possible role in the pathogenesis of asthma. Environ. Health Perspect. 1997, 105 (9), 972-978.

(23) Clausen G., Høst A., Toftum J., Bekö G., Weschler C. J., Callesen M., Buhl S., Ladegaard M., Langer S., Andersen B., Sundell J., Bornehag C. G., Sigsgaard T. Indoor Environment and Children's Health (IECH) - An ongoing epidemiological investigation on the association between indoor environmental factors in homes and kindergartens and children's health and wellbeing. Proceedings of the 9th International Healthy Buildings Conference 2009. Santanam S., Bogucz E. A., Peters C., Benson T., Eds.; Syracuse, NY, Paper No. 603.

(24) Weschler, C. J.; Nazaroff, W. W. Semivolatile organic compounds in indoor environments. Atmos. Environ. 2008, 42 (40), 9018-9040.

(25) Weschler, C. J.; Nazaroff, W. W. SVOC partitioning between the gas phase and settled dust indoors. Atmos. Environ. 2010, 44 (30), $3609-3620$.

(26) Langer, S.; Weschler, C. J.; Fischer, A.; Bekö, G.; Toftum, J.; Clausen, G. Phthalate and PAH concentrations in dust collected from Danish homes and daycare centers. Atmos. Environ. 2010, 44 (19), 2294-2301.

(27) Rudel, R. A.; Camann, D. E.; Spengler, J. D.; Korn, L. R.; Brody, J. G. Phthalates, alkylphenols, pesticides, polybrominated diphenyl ethers, and other endocrine-disrupting compounds in indoor air and dust. Environ. Sci. Technol. 2003, 37 (20), 4543-4553.

(28) Wallace, L. A., The Total Exposure Assessment Methodology (TEAM) Study: Summary and Analysis, 1987, EPA PB 88-100 060, U. S. Environmental Protection Agency, Washington, DC.

(29) Shields, H. C.; Fleischer, D. M.; Weschler, C. J. Comparisons among VOCs measured in three types of US commercial buildings with different occupant densities. Indoor Air 1996, 6 (1), 2-17.

(30) Ott, W. R. Environmental Statistics and Data Analysis; Ann Arbor: Lewis Publishers; 1995

(31) Downing, D. T.; Strauss, J. S. Synthesis and composition of surface lipids of human skin. J. Invest. Dermatol. 1974, 62 (3), 228244.

(32) Schmidt, C.; Penneys, N. S.; Ziboh, V. A.; Kiem, I.; Schlossberg, J. Cholesterol and cholesteryl ester content in normal and pathologic scale. J. Invest. Dermatol. 1977, 68 (4), 206-209.

(33) Nicolaides, N.; Fu, H. C.; Rice, G. R. The skin surface lipids of man compared with those of eighteen species of animals. J. Invest. Dermatol. 1968, 51 (2), 83-89.

(34) Lindholm, J. S.; Downing, D. T. Occurrence of squalene in skin surface lipids of the otter, the beaver and the kinkajou. Lipids 1980, 15 (12), 1062-1063.

(35) Sharaf, D. M.; Clark, S. J.; Downing, D. T. Skin surface lipids of the dog. Lipids 1977, 12 (10), 786-790.

(36) Wells, J. R.; Morrison, G. C.; Coleman, B. K. Kinetics and reaction products of ozone and surface-bound squalene. J. ASTM Int'l. 2008, 5 (7), 1-12.

(37) Gumulka, J.; Smith, L. L. Ozonization of Cholesterol. J. Am. Chem. Soc. 1983, 105 (7), 1972-1979.

(38) Dreyfus, M. A.; Tolocka, M. P.; Dodds, S. M.; Dykins, J.; Johnston, M. V. Cholesterol ozonolysis: kinetics, mechanism, and oligomer products. J. Phys. Chem. A 2005, 109 (28), 6242-8.

(39) Weitkamp, E. A.; Hartz, K. E.; Sage, A. M.; Donahue, N. M.; Robinson, A. L. Laboratory measurements of the heterogeneous oxidation of condensed-phase organic molecular makers for meat cooking emissions. Environ. Sci. Technol. 2008, 42 (14), 5177-82. 
(40) Toftum J., Clausen G., Bekö G., Callesen M., Sundell J., Bornehag C. G., Høst A., 2009. A questionnaire survey on dwelling characteristics and the prevalence of asthma and allergy among Danish children - IECH. Proceedings of the 9th International Healthy Buildings Conference. Santanam S., Bogucz E. A., Peters,C., Benson T., Eds.; Healthy Buildings 2009, Syracuse, NY, USA. Paper No: 613.

(41) Hilal, S. H.; Karickhoff, S. W.; Carreira, L. A., 2004. Prediction of the solubility, activity coefficient and liquid/liquid partition coefficient of organic compounds. QSAR Comb. Sci. 2004, 23 (9), 709-720.

(42) Wisthaler, A.; Tamas, G.; Wyon, D. P.; Strøm-Tejsen, P.; Space, D.; Beauchamp, J.; Hansel, A.; Märk, T. D.; Weschler, C. J. Products of ozone-initiated chemistry in a simulated aircraft environment. Environ. Sci. Technol. 2005, 39 (13), 4823-4832.

(43) Tamas, G.; Weschler, C. J.; Bako-Biro, Z.; Wyon, D. P.; StromTejsen, P. Factors affecting ozone removal rates in a simulated aircraft cabin environment. Atmos. Environ. 2006, 40 (32), 6122-6133.

(44) Weschler, C. J.; Wisthaler, A.; Cowlin, S.; Tamas, G.; StromTejsen, P.; Hodgson, A. T.; Destaillats, H.; Herrington, J.; Zhang, J.; Nazaroff, W. W. Ozone-initiated chemistry in an occupied simulated aircraft cabin. Environ. Sci. Technol. 2007, 41 (17), 6177-84.

(45) Coleman, B. K.; Destaillats, H.; Hodgson, A. T.; Nazaroff, W. W. Ozone consumption and volatile byproduct formation from surface reactions with aircraft cabin materials and clothing fabrics. Atmos. Environ. 2008, 42 (4), 642-654.

(46) Pandrangi, L. S.; Morrison, G. C. Ozone interactions with human hair: Ozone uptake rates and product formation. Atmos. Environ. 2008, 42 (20), 5079-5089.

(47) Wisthaler, A.; Weschler, C. J. Reactions of ozone with human skin lipids: Sources of carbonyls, dicarbonyls, and hydroxycarbonyls in indoor air. Proc. Natl. Acad. Sci. U.S.A. 2010, 107 (15), 6568-6575.

(48) Weschler, C. J. Ozone in indoor environments: Concentration and chemistry. Indoor Air 2000, 10 (4), 269-288.

(49) Nazaroff, W.; Gadgil, A.; Weschler, C., Critique of the use of deposition velocity in modeling indoor air quality. In Modeling of Indoor Air Quality and Exposure, Nagda, N., Ed. American Society for Testing and Materials: Philadelphia, 1993; pp 81-104.

(50) Hodgson, A. T.; Levin, H., Volatile organic compounds in indoor air: A review of concentrations measured in North America since 1990. LBNL Report 51715, 2003, Lawrence Berkeley National Laboratory, Berkeley, CA. 